\title{
Survey of Greener Ignition and Combustion Systems for Internal Combustion Engines
}

\author{
Wuqiao Luo, Yun Li \\ School of Engineering, University of Glasgow, \\ Glasgow G12 8LT, U.K. \\ w.luo.1@research.gla.ac.uk; Yun.Li@glasgow.ac.uk
}

\author{
Zhong Tian, Bo Gao, Ling Tong, Houjun Wang, \\ Baoqing Zeng \\ University of Electronic Science and Technology of \\ China, Chengdu, China
}

\begin{abstract}
The spark and compression ignition principles of petrol and diesel internal combustion engines (ICEs) have not advanced for a century. These do not lead to complete combustion and hence result in high exhaust emission and low energy efficiency. This paper presents a comprehensive survey on the attempts and developments of greener ignition and combustion systems for ICEs and points out that homogeneous charge microwave ignition (HCMI) holds the key to a perfect solution. Increasing the ignition volume has become a trend in research for high-performance, lean-burn and low-emission petrol engines. It started with increasing ignition points by adopting multi-point spark and lasers. The ignition volume is future increased by high energy and long endurance ignition as method of zone-based ignition. Production of transient plasma in ignition stage is the key point because combustion performance and flame front speed is related to volume of transient plasma. But the volume of ignition is still limited for high ignition energy requirement. The volume-based ignition methods, like HCMI, with bigger ignition volume which leads to better efficiency and low emission are assessed and compared. Many tests on physical engines have proved that HCMI offers significant performance, but the problem lies in a production-oriented design. Virtual prototyping through Computer-Automated Design would help in this regard and could lead to novel processes for Industry 4.0.
\end{abstract}

Keywords- internal combustion engine; ignition system; HCCI; HCMI; Industry 4.0

\section{INTRODUCTION}

With the rapid growth of automotive vehicles on the road worldwide [1], exhaust emissions from internal combustion engines (ICEs) have raised urgent concerns. The search has been on for new technologies to reduce the emissions by addressing this problem at root, i.e., by increasing the fuel efficiency through more thorough combustion, and not just by filtering unburnt mixture through catalytic conversion.

At present, the fuel efficiency of an ICE is typically between $25 \%$ and $40 \%$, and $40 \%$ of the energy released is lost through the exhaust gas $[2,3]$. Certain technologies have been developed to address these concerns of low fuel efficiency. Electrical and hydrogen fuel cell vehicles have gained much attention recently for their high energy efficiency of vehicle and zero emissions on the road [4-7]. However, their total energy efficiency is even lower than ICEs after accounting for multiple energy conversions; higher emission is expected is electricity generation and hydrogen generation [8]. Electric vehicles (HEVs) have been proven with economic benefits by the market, but

Wuqiao Luo is grateful to the China Scholarship Council and the University of Glasgow for a CSC scholarship. they have a slow market penetration, which reinforces that conventional vehicles will remain dominant in the next few decades. Other resorts like increasing the voltage of the electrical system of conventional vehicles from 12 volts to 42 volts, fuel economy can be improved with an estimated benefit between $9 \%$ and $12 \%$ [9]. But this change will affect the entire electronic supply chain, which is reluctant to those suppliers. Further, improvements by HEVs or 42-volts vehicles target at the system efficiency after the energy having been released and transformed as storable energy, and hence room still exists to address emission and efficiency at the root of energy transform.

For example, a lean combustion technology, which is desirable for its economic effect and low nitrogen oxide $\left(\mathrm{NO}_{\mathrm{x}}\right)$ emission, as exhaust gas recirculation (EGR) has been studied for modern engines to meet emissions targets. Both $\mathrm{NO}_{\mathrm{x}}$ emission and unburnt fuel are reduced for low burning temperature and re-burning of exhaust gas. However, high EGR rates may cause misfire at spark ignition (SI) [10]. Further, it is reported that ignition not only initiates combustion but also influences subsequent combustion [11]. For petrol engines with SI, ignition occurs between two electrodes about $2 \mathrm{~mm}$ apart. Only a negligible fraction $\left(10^{-3}\right)$ of the mass is ignited [12]. It takes 0.2-0.4 millisecond for the initial flame ball to grow to $1-1.5 \mathrm{~mm}$ after the spark onset [13]. The combustion is incomplete as the flame front propagates in a low speed, which is called the laminar combustion phase. Increasing the ignition volume has become a trend in research for high-performance, lean-burn and low-emission petrol engines. For diesel engines, compression ignition (CI) gives higher fuel-efficiency, but also higher $\mathrm{NO}_{\mathrm{x}}$ emissions due to a higher temperature. The drawbacks of SI and CI lead to the study of homogeneous charge compression ignition (HCCI) system, first proposed by Najt in 1983 [14]. However, challenge lays in HCCI is to change an open-loop control problem of the ignition timing to closed-loop, which requires accurate sensing and control of in-cylinder temperature and/or pressure. This has proved theoretically simple but practically impossible so far. An electromagnetic (EM) field based ignition is brought out in an U.S. Patent issued in 1952 [15]. Not only a large volume of fuel can be ignited at the same time, but also the ignition timing control can be realised by timing control of EM field formation. This EM field based ignition is named as microwave ignition (MI), homogeneous charge microwave ignition (HCMI) if the gas is homogeneous before ignition, because the EM field is formed by microwave resonant. HCMI is a promising 
solution for high fuel efficiency and low emission for the ignition happens in the whole space of cylinder head theoretically.

Through the comprehensive survey on efforts made so far to improve ignition and combustion of ICEs presented in this paper, a trend of increasing ignition volume is pointed out. Based on this aspect, the next section presents an overview of current ignition methods in three subsections: 1) point-based ignition; 2) zone-based ignition; 3) volume-based ignition. Then in section III method of HCMI is reviewed in depth and it is pointed out that HCMI holds the key to perfect solution. Future directions are discussed in section I based on the reviews in the former sections and conclusions are drawn in section $\mathrm{V}$.

\section{EXISTING TECHNIQUES FOR IMPROVING ENERGY EFFICIENCY IN IGNITION AND COMBUSTION}

It is a long way to fully understand the mechanisms of ignition and combustion. A general understanding is that some particles of the mixture become active radicals at ignition stage through heat or high electric field, and oxidation reaction happens between these active radicals. When the heat released by oxidation reaction is greater than heat radiation loss, the temperature of the combustible mixture continues to rise to create more active radicals and combustion begins. The key point of stable ignition is whether there exist enough active radicals during the initial ignition to maintain the chemical reaction chain. Hence the volume of ignited particles at the initial ignition defines three different ignition categories as: 1) point-based ignition; 2) zone-based ignition; 3) volume-based ignition. Besides the volume of ignition, the techniques of ignition in ICE also aim at lean combustion and pragmatic application. Also well premixed gas is pointed out as a key factor for combustion performance.

\section{A. Point-Based Ignition}

Comparing with the whole space of cylinder, the flame kernel of spark plug and laser ignition is so small that can be considered as a point in the space of cylinder head. Only a few particles are broken into active radicals around igniter, hence the chemical reaction starts within small area. Though multi-pointed ignition with multiple spark igniters or by laser-induced ignition may have better lean combustion limits than single-point ignition, the separated flame kernels are still with millimetre level diameters.

\section{1) Single-Point High-Energy SI}

Single-point high-energy SI can expand lean limits for conventional SI, though such improvement is limited. Lean combustion with excess air or high EGR would require higher ignition energy to ensure reliable ignition, which is to modify the circuit of ignition system to produce long duration sparks [16] or increase ignition voltage. But that didn't noticeably affect burning cycles due to the slow flame speed of the highly diluted combustible mixtures [17].

\section{2) Multi-Point SI}

Instead of raising ignition energy of spark igniter, multi-point SI is another direction to push the lean limit of combustion. Patent [18] describes a multi-point spark plug can create multiple sparks with a special electrode which has plural projections extending radially from the central. Another effort is made in [19] that at least 3 spark plugs are installed in a removable cylinder head to have multiple sparks when ignites. Although such multi-point ignition system enhances the combustion and prevent possible misfire by increasing ignition points, it does not raise the ignition and combustion efficiency or reduce emission significantly.

\section{3) Laser Ignition}

Laser ignition system has been under much attention recently for its many potential benefits, including the greater control over the timing and location of ignition, absence of electrodes and possibility to allow ignition in multiple locations [20]. Laser-induced spark ignition which depends on electrical breakdown at focal point of laser is descripted in [21]. It replace the spark plug with a laser plug and there is no need for plug replacement since it is without electrodes. However, the ignition efficiency improvement is negligible compare to traditional spark plug ones because it is only initiates the ignition at a single point [21] and only $30-70 \%$ of the incident laser energy can be utilised in laser-induced spark ignition [22]. Morsy et al. [22, 23] proposed a laser-induced cavity ignition which ignition occurs inside a conical cavity. A non-focused laser beam is directed into and confined in the conical cavity by multiple reflections at the surface of the cavity [23] where the energy is focused for ignition.

Though laser ignition has been proved and tested in lab for its reliability and feasibility, the practical implementation of this laser application has still to be fully realised in a commercial automotive application yet [23]. Some researchers have done the real engine experiments. Brake mean effective pressure (BMEP) and $\mathrm{NO}_{\mathrm{x}}$ emission have been evaluated in a real engine with laser ignition. But costs for installation of laser ignition would be a problem for commercial use [24].

\section{B. Zone-Based Ignition}

If the active radicals can be more than those in limited points like point-based ignition, it is expected the initial flame kernel would be bigger. Further, such active radicals help the flame propagate faster. In this category, more active radicals as transient plasma is produced by increasing ignition energy and lengthening ignition duration so as to enlarge the ignition volume.

\section{1) Through a High Voltage Pulse}

The transient plasma is produced by discharge between electrodes. In order to maximise the transient plasma, an electrode is places in a small recessed chamber in the cylinder connected to ground line [25]. Discharge happens between electrode and chamber which creates radial pattern arcs when high DC voltage is applied between them. It is disclosed in [25] that this ignition system has potential for improving lean combustion operation and is potentially useful for gasoline engine emissions reduction.

\section{2) Radio Frequency Corona Ignition}

In [26], a radio frequency (RF) corona ignition system is presented which adopts RF plasma jet to ignition the 
combustible mixture. Though the performance of radio frequency plasma for high pressure gasoline direct injection engines are tested by [26], the mismatch impedance of RF antenna would be the biggest challenge in this method. In operation around $90 \%$ of the radio frequency power was reflected from the actuator, and only $100 \mathrm{~W}$ were delivered to the plasma in the first prototype of ignition systems. With a matching network, the delivery power rise up to $380 \mathrm{~W}$. Impedance match for a various load is important and matching network design would be difficult if aiming at well controlled, reliable ignition system.

\section{3) Corona Railplug}

Corona happens between two parallel rails when electrically break down between the rails because high voltage is added between them. The corona would move from its initial place to the other end of rails in a cavity to ignite combustible mixture. In [27], a plasma jet is produced during the process of corona moving resulting in a zone-based ignition with a high speed of flame propagation

\section{Volume-Based Ignition}

In zone-based ignition methods, the ignition occurs in a pre-determined area, i.e., discharge chamber as in [25], between rails as in [27]. The mechanical design of cylinder must be changed, along with the igniter, to enlarge the volume of ignition. In volume-based ignition, low temperature combustion (LTC), HCCI and MI are introduced not only for its large volume of ignited gas when ignition happens, but also for the ignition location is no longer limited by the mechanical structure, but could be the whole space of cylinder head.

\section{1) Diesel Low Temperature Combustion}

In diesel engine, the temperature of combustion is much higher than in petrol engine. Hence the $\mathrm{NO}_{\mathrm{x}}$ emission is higher though the efficiency is higher than in petrol ones. LTC is introduced by manufacturers for premixed combustible mixture with a better efficiency and lower emission. High level of EGR and directinjection techniques are adopted to meet LTC [28].

The ignition happens which the fuel is injected into hot air, hence how and when the fuel are injected effects the ignition and combustion. For more contact area and longer time between injection and ignition, the mixture of air and fuel would be mixed better and the ignition volume would be bigger. Various fuel-injector types and techniques have been studied. Double injection technique was used to premix the air-fuel before ignition [29]. The first injection was used as an early injection for fuel diffusion and the second injection was used as an ignition trigger for all the fuel. However, liquid-spray impingement on the cylinder liner often occurs for very early injection [28]. Narrow angle direct injection is investigated by $\mathrm{B}$. Walter which a narrow spray cone angle was selected [30]. Instead of premix the air-fuel mixture by early injection, another approach is to delay ignition to allow more time for premixing, which the ignition occurs at early stage of the expansion stoke. Injection timing retarded and increasing EGR rate can help prolong the ignition delay [31]. Performances of combustion is studied under different EGR levels and injection timings in [32]. Although high EGR levels contribute to complete combustion, the diluted mixtures increase $\mathrm{CO}$ emissions. Injection the fuel at early timings helps alleviated this problem, but did not eliminate it [32].

\section{2) Homogeneous Charge Compression Ignition}

HCCI combines characteristics of ignition in conventional gasoline engine and diesel engines. The advantage of the HCCI is that the fuel and air are homogeneous which the auto-ignition would occur at multiple locations simultaneously, not a single point ignition like for the SI system.

With HCCI systems it is possible to save up to $30 \%$ on fuel consumption compared to traditional SI engines. The peak temperature is significantly lower than it would be during a typical spark ignition and the $\mathrm{NO}_{\mathrm{x}}$ level is negligible [33]. Future, a HCCI engine can operate on most kind of fuels such as gasoline, diesel, and the majority of alternative fuels, like compressed natural gas $(\mathrm{CNG})$ or liquefied petroleum gas (LPG) [34]. Unfortunately, the control of the temperature is difficult since pressure and temperature need to be monitored for a closed loop control and can only be adjusted through the inlet and outlet valves.

\section{3) Microwave Ignition}

A U.S. Patent issued in 1952 [15] discloses an ignition system with high frequency waves including radio frequency and microwave. Like laser, microwave can also be used as energy source for ignition. A microwave is electromagnetic radiation having a frequency within the range of $10^{9} \mathrm{~Hz}$ to $10^{12} \mathrm{~Hz}$, which has longer wavelength than laser.

In early research, magnetron was source of microwave for the cost reason, but the size and the fixed resonant frequency make magnetron infeasible for practical application. With the help of high power semiconductor, though power efficiency of which is about $20 \%$ lower than magnetron, the microwave source can be small and flexible enough to fit into a vehicle. Besides the potential of extreme lean combustion due to an actually whole space ignition by MI, ignition timing is controlled by timing of microwave emitting. Though MI is relatively new and with few accomplished, but it is the most promising and practical method and should have received more attention.

The name of MI varies in literature. This paper mainly focus on homogeneous charge microwave ignition (HCMI) where the combustible gas is homogeneous before ignition induced by microwave resonant. Up to this day, there are two major methods for microwave ignition, based on the fundamentals of breakdown of fuel molecules. The first method is to ignite by high temperature because of resonating of the pole-like molecules. These molecules show characteristic resonant frequencies. Thus a certain energy level microwave can be added to a specified molecule to induce the resonation. Such resonation makes the temperature of the specified molecule raise till breakdown. The second one is using cavity resonation to breakdown the molecules of fuel, 
which the microwave would resonant in a cavity to break the air-fuel mixtures inside it. Both of MI types would be discussed in section III in depth.

\section{HOMOGENEOUS CHARGE MiCROWAVE IGNITION}

The two types of mechanisms in MI are molecule resonant breakdown and strong electric field breakdown. Though there hasn't been an extensive theory on the quantum-mechanical process of molecule resonant breakdown. But in [35], paired electrons and its symmetry in chemical bonds are influenced by electric and magnetic moments which are generated with distributed parameters using a self-supporting oscillation system working under a superposition of mode conditions. When the chemical bonds in hydrocarbons are broken by a certain frequency microwave, radical chain reaction will be set off, which is beginning of combustion. Further, some technical procedures suggest that with surprisingly low excitation energy in the classic sense, chemical processes can be accelerated because of the interaction of electromagnetic radiation and hydrocarbons [35]. In strong electric field breakdown, a stable and strong electric field is created by microwave resonant. When the microwave power is big enough, the molecules will be breakdown under such electric field.

\section{A. Molecule Resonant Breakdown}

The breakdown happens due to the energy absorbed from microwave in the form of kinetic energy. Makita and Ikeda patented an apparatus for ignition with microwave as assistance $[36,37]$. It adopts a similar ignition structure as spark plug. The difference lies on a miniature microwave antenna which emits microwave to the initial plasma generated by spark plug. It can enlarge plasma as much as 300 times of the spark discharge alone, with high working pressure to $2.0 \mathrm{MPa}$. This method can also be referred as plasma enhanced ignition because the main idea is to create as much plasma as possible at the initial ignition time so as to improve ignition and combustion performance. Through experiments in single-cylinder research engines, the combustion stability is improved and the lean limit of equivalence ratio is increased from 0.59 to 0.49 [36].

The Micro Wave Ignition AG (MWI) in Germany have filed several patents and papers for a microwave ignition system since 2005 [35, 38, 39]. The mechanism of ignition is stated briefly in [35], and the implement of this method is revealed in a patent [38]. If the frequency of microwave corresponds with the splitting of the atomic or molecular energy level in air-fuel mixtures, stimulated emission or absorption of electromagnetic radiation occurs which finally leads to the stimulation of the chemical bonding and thus setting off the radical chain reaction [35]. This space ignition method can be utilised to save up to $30 \%$ fuel consumption and prevents up to $80 \%$ of pollutant emissions. Further, it is point out there is no thorough theory to explain how microwave influence the chemical bonds in hydrocarbons, but it implied that traditional understanding about reaction between microwave and chemical bonds might need to be refined. They had an ultimate goal of supplying every new vehicle with their technology within ten years [39].

\section{B. Strong Electric Field Breakdown}

The microwave resonates inside a cavity which forms a steady and strong electric field to breakdown air-fuel mixtures. The advantages of resonant breakdown are that the air-fuel mixture has a lower breakdown voltage when using microwave and the resonant cavity itself is its own amplifier [40]. The problem in microwave resonant in a cavity is how to decide frequency of microwave to meet the resonant requirement of the cavity.

In [41] the shape of cavity is modified to ensure that resonation under fixed frequency. A similar solution, presented by West Virginia University, is to build a small cavity inside the igniter instead of an extra chamber which need to change the shape of engine cylinder [40, 42]. A high voltage is generated at the open end because of resonation. This high voltage, like generated from ignition coil in conventional spark ignition system, is used to breakdown air-fuel mixtures for ignition [40]. Meanwhile the resonant frequency can fixed in accordance with features of the cavity. The most notable one is called as a quarter wave coaxial cavity resonant (QWCCR) which where the length of the cavity is a quarter of the wavelength. In 2002, Schleupen patented an similar ignition device with QWCCR and high-voltage jointly mounting to a flexfilm as the substrate [43]. In 2003, Schmidt and Ruoss published a patent for a microwave igniter with resonant frequency at multiple times of the resonant frequency under QWCCR [44]. Unfortunately, with the QWCCR the ignition occurs just around the centre electrode of the resonator, which dissipates the advantage of using the microwave ignition system.

Another solution is given by the group in University of Glasgow. They use antenna to transmit the microwave into engine cylinder. When the frequency meets the resonant requirement of cylinder, the resonation would generate a steady and strong electric field inside the cylinder. The problems lie at this method is to find the resonant frequency for the irregular shape of cylinder head and to couple microwave into cylinder. The effort have made in computer simulations and digital prototyping of HCMI systems and in applying computational intelligence to their design and optimised zero prototyping in order to bring about this revolution [45, 46]. An HCMI system is divided into three parts: microwave source, transmission line, and engine cylinder (resonator). Once the control signal is sent the microwave is generated by the source and transferred to the resonator through the transmission line. The source frequency is equivalent to the natural frequency of the combustion chamber. The ignition timing of an HCMI system is easier to control than of an HCCI system simply by controlling the timing of the generation of the microwave in an open-loop manner similar to the SI system. To breakdown the air-fuel mixture inside the resonance an electric field intensity of $1 \times 10^{5} \mathrm{~V} / \mathrm{m}$ is required [47]. Providing a resonance condition and hence an enhanced electric field strength for a viable design of the HCMI system is the main goal. Table I gives compares of different methods of HCMI. 
TABLE I. COMPARES OF DIFFERENT METHODS OF HCMI

\begin{tabular}{|c|c|c|c|}
\hline Institution & Method & Accomplishment & Further work \\
\hline $\begin{array}{c}\text { Imagineering, Inc., } \\
\text { Japan [36, 37] }\end{array}$ & $\begin{array}{c}\text { Microwave } \\
\text { plasma assistant }\end{array}$ & $\begin{array}{c}\text { Lean limit reach to } 0.61 ; 300 \text { times } \\
\text { OH radicals of conventional spark; } \\
\text { under 2.0 MPa }\end{array}$ & $\begin{array}{c}\text { Feasibility for vehicle } \\
\text { application. }\end{array}$ \\
\hline $\begin{array}{c}\text { MWI Micro Wave } \\
\text { Ignition AG [35,38,39] }\end{array}$ & MWI & $\begin{array}{c}\text { Reduce by } 30 \% \text { fuel consumption and } \\
80 \% \text { emission }\end{array}$ & $\begin{array}{c}\text { Prototype for the large-size } \\
\text { engine. }\end{array}$ \\
\hline $\begin{array}{c}\text { West Virginia } \\
\text { University [40, 42] }\end{array}$ & QWCCR & $\begin{array}{c}\text { Shorter ignition time; lean limit reach } \\
\text { to } 0.8\end{array}$ & $\begin{array}{c}\text { Impedance mismatch of } \\
\text { microwave transmit. }\end{array}$ \\
\hline $\begin{array}{c}\text { University of Glasgow } \\
{[45,46]}\end{array}$ & $\begin{array}{c}\text { Resonant in } \\
\text { cylinder }\end{array}$ & $\begin{array}{c}\text { CAutoD based design for microwave } \\
\text { coupling problem }\end{array}$ & $\begin{array}{c}\text { MI simulation and CAutoD } \\
\text { based design of HCMI system }\end{array}$ \\
\hline
\end{tabular}

\section{FUTURE DIRECTIONS}

For high-performance, lean-burn and low-emission petrol engines, increasing the ignition volume and reduce the combustion temperature should be aimed by future works in ignition and combustion of ICEs. HCMI, though, is a relatively new method for ignition, it has the potential for both space ignition and low temperature combustion. Also with the development of power semiconductors, the application in vehicles is foreseeable. For recent research in HCMI, most of the engine tests are in lab. There is a long way for real vehicle application and road tests. In this section, two directions of HCMI research are given, to shine a light towards practical application in and vehicles.

\section{A. Enhancing Design of Experiments and Tests of Electromagnetic Properties}

Experimental research on ICE ignition system is mainly on feasibility with a physical engine. This has not covered electromagnetic (EM) properties of ignition and combustion. It is necessary to investigate interactions between the EM field and the particles or particles themselves in an ICE environment. In particular, breakdown condition of fuel particles and EM properties of plasma should have drawn more attention. How the complex environment of pressure, temperature, shape and medium of gas would affect the breakdown condition is still unknown, though the breakdown condition is the premise of all the experiments and simulations on ignition. In most research, a rough assumption is made about the breakdown condition. Following the fuel-air mixture being broken down, particles form a transient plasma state. Properties of plasma have been studied to enhance ignition. However, in a high pressure and varying temperature environment as in an ICE cylinder, the properties of plasma in such an EM field are not explicit.

\section{B. Virtual-Physical Design for Manufacture}

The time and cost associated with physical prototyping should be taken into consideration as early as the conceptual design stage. Virtual prototyping is a sound solution because by replacing an actual prototype with a digital one, much time and cost would be saved in design through prototyping. With intelligent algorithms and Computer-Automated Design, optimizing the prototype would be much more efficient than the conventional manual trial-and-error method. Towards Industry 4.0 and smart factory, product-oriented design-prototype integration would deliver a higher product feasibility and performance in the future.

\section{CONCLUSION}

A comprehensive survey on the attempts and developments of greener ignition and combustion systems for ICEs has been presented in this paper, covering methods from a single point ignition to volumetric ignition. Plasma ignition is also discussed in this paper, but a low-power solution is a long way off. HCMI appears to hold the key to a perfect solution, while other practically feasible methods such as corona and laser ignitions have suffered from incomplete combustion.

Many tests on physical engines have proved that HCMI offers significant performance, but the problem lies in a production-oriented design. Virtual prototyping through Computer-Automated Design would help in this regard and could lead to novel processes for Industry 4.0.

\section{REFERENCES}

[1] S. Taryma, J. A. Ejsmont, G. Ronowski, B. SwieczkoZurek, P. Mioduszewski, M. Drywa, et al., "Road texture influence on tire rolling resistance," Key Engineering Materials, 2014. 597: p. 193-198.

[2] O. A. Kutlar, H. Arslan and A. T. Calik, "Methods to improve efficiency of four stroke, spark ignition engines at part load," Energy Conversion and Management, 2005. 46(20): p. 3202-3220.

[3] A. Thiruvengadam, S. Pradhan, M. Besch, D. Carder and O. Delgado, "Heavy-duty vehicle diesel engine efficiency evaluation and energy audit." 2014, Mechanical and Aerospace Department, West Virginia University, The International Council on Clean Transportation, Washington, DC.

[4] C. Chan, "The state of the art of electric and hybrid vehicles," Proceedings of the IEEE, 2002. 90(2): p. 247275.

[5] K. Frenken, M. Hekkert and P. Godfroij, "R\&d portfolios in environmentally friendly automotive propulsion: Variety, competition and policy implications," Technological Forecasting and Social Change, 2004. 71(5): p. 485-507.

[6] O. Andersen, Implementation of hydrogen gas as a transport fuel, in Unintended consequences of renewable energy. 2013, Springer. p. 47-54.

[7] S. A.-B. Maher AR, "Effect of compression ratio, equivalence ratio and engine speed on the performance and emission characteristics of a spark ignition engine using hydrogen as a fuel," Renewable Energy, 2004. 29(15): p. 2245-2260.

[8] H. Helms, M. Pehnt, U. Lambrecht and A. Liebich. "Electric vehicle and plug-in hybrid energy efficiency and life cycle emissions." in 18th International Symposium Transport and Air Pollution, Session. 113. 2010. 
[9] B. Simpkin, R. Marco, C. D. A. CRF, M. Abele, G. Heuer, A. Ferré, et al., "Improved energy efficiency for conventional vehicles through an enhanced dual voltage architecture and new components with an attractive costbenefit ratio," 2011.

[10]T. Briggs, T. Alger and B. Mangold, "Advanced ignition systems evaluations for high-dilution si engines." 2014, SAE Technical Paper.

[11]O. Yaşar, Plasma modeling of ignition for combustion simulations, in Computational science-iccs 2001. 2001, Springer. p. 1147-1155.

[12]J. Tagalian and J. B. Heywood, "Flame initiation in a sparkignition engine," Combustion and Flame, 1986. 64(2): p. 243-246.

[13]S. Pischinger and J. B. Heywood, "A model for flame kernel development in a spark-ignition engine," Symposium (International) on Combustion, 1991. 23(1): p. 1033-1040.

[14]P. M. Najt and D. E. Foster, "Compression-ignited homogeneous charge combustion." 1983, SAE Technical paper.

[15]E. G. Linder. "Internal-combustion engine ignition," United States 2617841, 1952. Patent

[16]W. R. Aiman, "Extended spark duration improves engine operation at high exhaust gas recirculation rates," Combustion Science and Technology, 1977. 15(3-4): p. 129-136.

[17]J. D. Dale, M. Checkel and P. Smy, "Application of high energy ignition systems to engines," Progress in energy and combustion science, 1997. 23(5): p. 379-398.

[18]R. J. Schaus. "Spark plug with multi-point firing cap," United States 6608430, 2003. Patent

[19]J. A. Davis. "Multipoint spark ignition system," United States 4805570, 1989. Patent

[20]T. X. Phuoc, "Laser-induced spark ignition fundamental and applications," Optics and Lasers in Engineering, 2006. 44(5): p. 351-397.

[21]D. Bradley, C. G. W. Sheppard, I. M. Suardjaja and R. Woolley, "Fundamentals of high-energy spark ignition with lasers," Combustion and Flame, 2004. 138(1-2): p. 55-77.

[22]M. Morsy, Y. Ko and S. Chung, "Laser-induced ignition using a conical cavity in $\mathrm{ch}<\mathrm{sub}>4</$ sub $>$-air mixtures," Combustion and flame, 1999. 119(4): p. 473-482.

[23]M. H. Morsy, "Review and recent developments of laser ignition for internal combustion engines applications," Renewable and Sustainable Energy Reviews, 2012. 16(7): p. $4849-4875$.

[24]G. Herdin, J. Klausner, E. Wintner, M. Weinrotter, J. Graf and K. Iskra. "Laser ignition: A new concept to use and increase the potentials of gas engines." in ASME 2005 Internal Combustion Engine Division Fall Technical Conference. 673-681. 2005.

[25]C. D. Cathey, T. Tang, T. Shiraishi, T. Urushihara, A. Kuthi and M. A. Gundersen, "Nanosecond plasma ignition for improved performance of an internal combustion engine," Plasma Science, IEEE Transactions on, 2007. 35(6): p. 1664-1668.

[26]G. Bachmaier, R. Baumgartner, D. Evers, R. Freitag, T. Hammer and G. Lins, "Radio frequency ignition system for gasoline direct injection engines," international Journal of Plasma Environmental Science \& Technology, 2012. 6(2): p. $140-148$.

[27]J. Ellzey, M. Hall, X. Zhao and H. Tajima, "Computational and experimental study of a railplug igniter," Experiments in fluids, 1993. 14(6): p. 416-422.

[28]J. E. Dec, "Advanced compression-ignition enginesunderstanding the in-cylinder processes," Proceedings of the Combustion Institute, 2009. 32(2): p. 2727-2742.
[29]R. Hasegawa and H. Yanagihara, "Hcci combustion in di diesel engine." 2003, SAE Technical Paper.

[30]B. Walter and B. Gatellier, "Development of the high power nadi ${ }^{\mathrm{TM}}$ concept using dual mode diesel combustion to achieve zero nox and particulate emissions." 2002, SAE Technical Paper.

[31]S. Kimura, O. Aoki, Y. Kitahara and E. Aiyoshizawa, "Ultra-clean combustion technology combining a lowtemperature and premixed combustion concept for meeting future emission standards." 2001, SAE Technical Paper.

[32]S. Kook, C. Bae, P. C. Miles, D. Choi and L. M. Pickett, "The influence of charge dilution and injection timing on low-temperature diesel combustion and emissions." 2005, SAE Technical Paper.

[33]J. Warnatz, U. Maas and R. W. Dibble, Combustion: Physical and chemical fundamentals, modeling and simulation, experiments, pollutant formation. 2006: Springer.

[34]K. Epping, S. Aceves, R. Bechtold and J. Dec, "The potential of hcci combustion for high efficiency and low emissions." 2002, SAE Technical Paper.

[35]N. Hirsch and A. Gallatz, "Space ignition method using microwave radiation," MTZ worldwide, 2009. 70(3): p. 3235.

[36]Y. Ikeda, A. Nishiyama and M. Kaneko, "Microwave enhanced ignition process for fuel mixture at elevated pressure of 1mpa," regulation, 2009. 1: p. 2.

[37]M. Makita and Y. Ikeda. "Ignition or plasma generation apparatus," United States 8226901, 2012. Patent

[38]V. Gallatz, N. Hirsch and I. Tarasova. "Fuel ignition process for engine combustion chamber involves creating microwave radiation in combustion chamber from source outside it," DE 10356916 B3, 2005. Patent

[39]V. Gallatz, N. Hirsch and I. Tarasova. "Method for igniting combustion of fuel in a combustion chamber of an engine, associated device and engine," United States US7770551 B2, 2010. Patent

[40]R. Stiles, G. J. Thompson and J. E. Smith, "Investigation of a radio frequency plasma ignitor for possible internal combustion engine use." 1997, SAE Technical Paper.

[41]K. Kimura, A. Endo and J. Takezaki. "Ignition system for internal combustion engine," United States 4446826, 1984. Patent

[42]F. A. Pertl and J. E. Smith, "Electromagnetic design of a novel microwave internal combustion engine ignition source, the quarter wave coaxial cavity igniter," Proceedings of the Institution of Mechanical Engineers, Part D: Journal of Automobile Engineering, 2009. 223(11): p. 1405-1417.

[43]R. Schleupen. "Ignition device for a high-frequency ignition," United States 6357426, 2002. Patent

[44]H.-O. Ruoss and E. Schmidt. "Device for igniting an airfuel mixture in an internal combustion engine," United States 7204220, 2003. Patent

[45]Y. Li, F. Sun and A. Capuano. "Em field enabled timing control of heci engines." in Proc 7th Asia-Pacific Conference on Control and Measurement. 39-44. Nyingchi, Tibet, China 2006.

[46]L. Schoning and Y. Li. "Multivariable simulation on a homogeneous charged microwave ignition system." in Automation and Computing (ICAC), 2012 18th International Conference on. 1-6. 2012.

[47]F. Lambert, L. Guido and T. Manfred. "Ignition and combustion support device using microwave technology for a gasoline engine," WO 9937911A, 1999. Patent 